\title{
Repurposing atovaquone: Targeting mitochondrial complex III and OXPHOS to eradicate cancer stem cells
}

\author{
Marco Fiorillo ${ }^{1,2,3}$, Rebecca Lamb ${ }^{1}$, Herbert B. Tanowitz ${ }^{4}$, Luciano Mutti ${ }^{5}$, Marija \\ Krstic-Demonacos ${ }^{5}$, Anna Rita Cappello ${ }^{3}$, Ubaldo E. Martinez-Outschoorn ${ }^{6}$, \\ Federica Sotgia ${ }^{1,2}$ and Michael P. Lisanti, ${ }^{1,2}$ \\ ${ }^{1}$ The Breast Cancer Now Research Unit, Institute of Cancer Sciences, Cancer Research UK Manchester Institute, University \\ of Manchester, Manchester, UK \\ 2 The Manchester Centre for Cellular Metabolism (MCCM), Institute of Cancer Sciences, Cancer Research UK Manchester \\ Institute, University of Manchester, Manchester, UK \\ ${ }^{3}$ The Department of Pharmacy, Health and Nutritional Sciences, The University of Calabria, Cosenza, Italy \\ ${ }^{4}$ Department of Medicine and Pathology, Albert Einstein College of Medicine, Bronx, NY, USA \\ ${ }^{5}$ School of Environment and Life Sciences, University of Salford, Salford, UK \\ ${ }^{6}$ The Sidney Kimmel Cancer Center, Philadelphia, PA, USA \\ Correspondence to: Michael P. Lisanti, email: michaelp.lisanti@gmail.com \\ Federica Sotgia, email: fsotgia@gmail.com \\ Keywords: atovaquone, tumor-initiating cells (TICS), mitochondria, OXPHOS, cancer stem-like cells (CSCS) \\ Received: January 08, $2016 \quad$ Accepted: January 27, $2016 \quad$ Published: April 30, 2016
}

\section{ABSTRACT}

Atovaquone is an FDA-approved anti-malarial drug, which first became clinically available in the year 2000. Currently, its main usage is for the treatment of pneumocystis pneumonia (PCP) and/or toxoplasmosis in immune-compromised patients. Atovaquone is a hydroxy-1,4-naphthoquinone analogue of ubiquinone, also known as Co-enzyme Q10 (CoQ10). It is a well-tolerated drug that does not cause myelo-suppression. Mechanistically, it is thought to act as a potent and selective OXPHOS inhibitor, by targeting the CoQ10-dependence of mitochondrial complex III. Here, we show for the first time that atovaquone also has anti-cancer activity, directed against Cancer Stem-like Cells (CSCs). More specifically, we demonstrate that atovaquone treatment of MCF7 breast cancer cells inhibits oxygen-consumption and metabolically induces aerobic glycolysis (the Warburg effect), as well as oxidative stress. Remarkably, atovaquone potently inhibits the propagation of MCF7-derived CSCs, with an IC-50 of $1 \mu \mathrm{M}$, as measured using the mammosphere assay. Atovaquone also maintains this selectivity and potency in mixed populations of CSCs and non-CSCs. Importantly, these results indicate that glycolysis itself is not sufficient to maintain the proliferation of CSCs, which is instead strictly dependent on mitochondrial function. In addition to targeting the proliferation of CSCs, atovaquone also induces apoptosis in both CD44+/CD24low/- CSC and ALDH+ CSC populations, during exposure to anchorage-independent conditions for 12 hours. However, it has no effect on oxygen consumption in normal human fibroblasts and, in this cellular context, behaves as an anti-inflammatory, consistent with the fact that it is well-tolerated in patients treated for infections. Future studies in xenograft models and human clinical trials may be warranted, as the IC-50 of atovaquone's action on CSCs $(1 \mu \mathrm{M})$ is $>50$ times less than its average serum concentration in humans. 


\section{INTRODUCTION}

Cancer Stem-like Cells (CSCs) are a sub-population of cancer cells that have been shown to be resistant to conventional chemo- and radio-therapy [1-4]. Residual CSCs left behind after clinical treatment are considered responsible for the re-growth of tumors and for their metastatic dissemination $[5,6]$. Thus, much effort has been devoted to the development of agents that are able to specifically target CSCs. Most approaches have focused on the targeting of signaling pathways necessary for their survival, expansion or self-renewal, as well as CSC-specific cell surface markers [7-10]. Other strategies include the possibility to induce CSC differentiation or the targeting of the CSC "niche" [11-14].

CSCs are strictly dependent on mitochondrial biogenesis, as well as mitochondrial function, for their clonal expansion. We have shown that pharmacological inhibition of the formation of new mitochondria is sufficient to block breast CSCs. In this regard, we have demonstrated that treatment with doxycycline, an inhibitor of mitochondrial ribosomes, or with XCT790, an inverse agonist of Estrogen-Related Receptor $\alpha$ (ERR $\alpha)$, a cofactor of PGC1 $\alpha$ that is required for the transcription of mitochondrial genes and mitochondrial biogenesis [15, 16], was sufficient to reduce mammosphere formation and bona-fide CSC markers [17, 18]. Similarly, the antimicrobial tigecycline selectively killed acute myeloid leukemia stem cells, by inhibition of mitochondrial translation [19]. Moreover, treatment with oligomycin A, an inhibitor of the ATP synthase, greatly reduced mammosphere formation [20]. Similarly, metformin, which has complex I inhibitory effects, induced rapid apoptosis of pancreatic CSCs [21]. Salinomycin, an antibiotic that was recently identified as a selective inhibitor of CSCs [22] has been shown to reduce cell survival, at least partially, by impairing mitochondrial bioenergetic performance [23]. Finally, pyrvinium pamoate, an FDA-approved anti-parasitic agent, behaves as an OXPHOS inhibitor targeting mitochondrial complex II and efficiently prevents mammosphere formation in the nano-molar range, with an IC-50 of $50 \mathrm{nM}$ [18]. However, pyrvinium pamoate is not absorbed efficiently from the gut, impeding its use for systemic anti-cancer therapy. Taken together, these studies provide a solid foundation and proof-of-concept for the new therapeutic strategy of targeting mitochondrial function to eradicate stem-like cancer cells.

In an ongoing search for targeted, yet safe, mitochondrial inhibitors, we identified atovaquone, a complex III inhibitor, that was originally developed to block the mitochondrial respiration of Plasmodium falciparum and other protozoa [24]. Atovaquone is a safe, FDA-approved drug, used for malaria prevention, and for the prevention and treatment of pneumocystis pneumonia and toxoplasmosis in HIV patients [25,
26]. Atovaquone can be administered alone as a liquid suspension (brand name Mepron) or in combination with Proguanil (brand name Malarone). Atovaquone is a highly lipophilic compound, with limited solubility in water. The bioavailability of atovaquone is dependent on its formulation and the diet, and its absorption is enhanced by high-fat food intake. Importantly, with current oral formulations, the average serum concentration of atovaquone in humans is $>50 \mu \mathrm{M}$.

Atovaquone is an extremely non-toxic OXPHOS inhibitor. Remarkably, attempts to suicide by overdosing on atovaquone, by taking three to 42 -fold the normal dose, resulted in few, if any, side effects. Atovaquone [trans-2-[4-(4-chlorophenyl)cyclohexyl]-3-hydroxy-1,4naphthalene-dione] is a quinone that functions as a competitive inhibitor of co-enzyme Q10, specifically inhibiting the mitochondrial electron transport chain in mitochondria isolated from Plasmodium falciparum at the cytochrome bc1 complex (Complex III) [27, 28]. Consistent with these findings, atovaquone has been shown to depolarize malarial mitochondria, resulting in a loss of mitochondrial function [24].

However, atovaquone efficacy was never previously tested in CSCs. Here, we set out to evaluate if atovaquone is an inhibitor of mitochondrial function in cancer cells and if it can be used as a targeted agent for breast CSCs.

\section{RESULTS}

\section{Atovaquone, a 'safe' OXPHOS inhibitor that potently targets cancer stem cells}

The aim of this study is to evaluate if atovaquone (Figure 1) is a potent inhibitor of mitochondrial function in cancer cells and if it can be used as a targeted agent for breast CSCs.

Towards this end, the metabolic profile of MCF7 breast cancer cells treated with increasing concentrations of atovaquone was assessed using the Seahorse XF-e96 analyzer. Atovaquone treatment markedly inhibits the mitochondrial respiration of MCF7 cells, with significant reductions in basal respiration, maximal respiration, and ATP levels (Figure 2). Moreover, atovaquone treatment increases aerobic glycolysis in MCF7 cells, with significant increases in glycolysis, glycolytic reserve, and glycolytic reserve capacity (Figure 3A-3E). The calculation of the Cell Energy Profile, obtained by plotting Oxygen Consumption Rates (OCR) against ExtraCellular Acidification Rates (ECAR), demonstrates that atovaquone shifts MCF7 cells from an oxidative state to a glycolytic state (Figure 3F).

To further characterize the mitochondrial function of MCF7 cells after treatment with atovaquone, MCF7 cells were stained with various metabolic probes and 
analyzed by FACS. Atovaquone decreases mitochondrial mass, as assessed with MitoTracker Deep-Red (Figure 4A), and mitochondrial membrane potential, as assessed with MitoTracker Orange (Figure 4B). The ratio of mitochondrial membrane potential (MitoTracker Orange) versus mitochondrial mass (MitoTracker Deep-Red) was calculated, showing that atovaquone significantly decreases the mitochondrial membrane potential per mitochondria (Figure 4C). We next determined Reactive Oxygen Species (ROS) levels using the CM-H DCFDA probe by FACS. Note that atovaquone increases ROS levels, as expected (Figure 4D). Taken together, these

Targeting Mitochondrial OXPHOS: Complex III

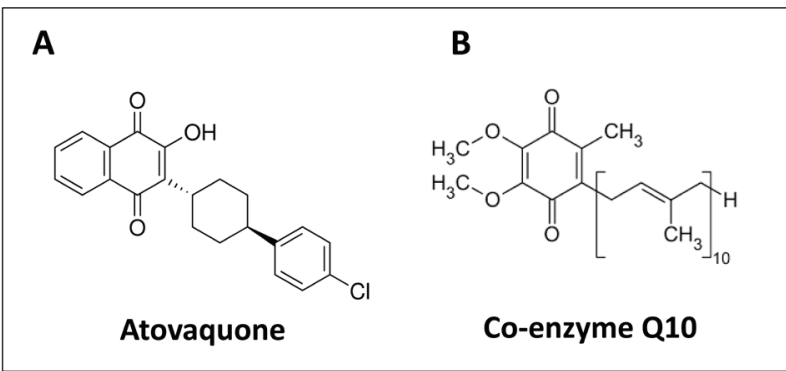

\section{Cytochrome bc1 Complex}

(MT-CYB)

Figure 1: Atovaquone: Comparison with the structure of CoQ10. Note that atovaquone A. is highly structurallyrelated to CoQ10 B. and was first designed to target the MTCYB subunit of Cytochrome bc 1 (mitochondrial complex III) in malarial parasites. data are consistent with the fact that atovaquone acts as a mitochondrial inhibitor in cancer cells, greatly impairing mitochondrial respiration, with a compensatory increase in glycolysis.

We next asked if atovaquone functions as a mitochondrial inhibitor specifically for cancer cells, or if it affects all types of mammalian cells. To this end, we assessed the metabolic profile of normal human fibroblasts treated with atovaquone for 48 hours using the Seahorse XF-e96 analyzer. Surprisingly, atovaquone does not inhibit at all the basal respiration, maximal respiration, and ATP levels of normal human fibroblasts, but rather we observed a slight, but not significant, increase in mitochondrial respiration (Figure 5A-5D). The glycolytic profile of normal human fibroblasts treated with atovaquone was also assessed using the Seahorse XF-e96 analyzer. Significant increases in glycolysis, and glycolytic reserve were observed experimentally, indicating that atovaquone increases glycolysis in normal human fibroblasts (Figure 6A-6E). Interestingly, in contrast to what we observed for MCF7 cancer cells, plotting of OCR against ECAR shows that atovaquone does not alter the metabolic state of normal human fibroblasts (Figure 6F).

We next measured ROS levels in human fibroblasts treated with atovaquone. Note that atoquavone increases ROS levels (Figure 7A). An increase in ROS levels may induce the activation of stress-induced responses pathways, such as HIF pathway, and/or pro-inflammatory signaling, such as NFKB, which are potentially toxic

\section{A}

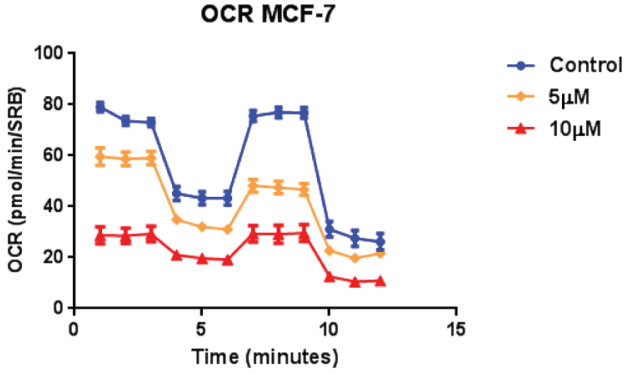

B Basal respiration MCF-7

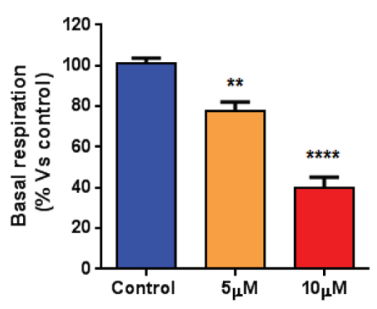

C

Maximal respiration MCF-7

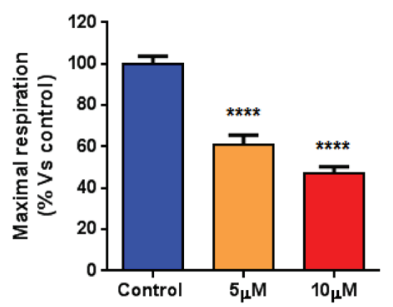

D

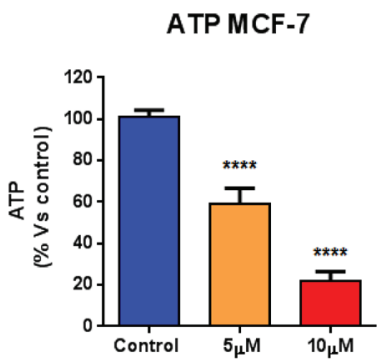

Figure 2: Atovaquone treatment inhibits the mitochondrial respiration of MCF7 breast cancer cells. The metabolic profile of MCF7 cell monolayers treated with atovaquone $(5 \mu \mathrm{M}$ and $10 \mu \mathrm{M})$ for 48 hours was assessed using the Seahorse XF-e96 analyzer. A. The tracing of 3 independent experiments is shown. B., C., D. Significant reductions in basal respiration, maximal respiration, and ATP levels were observed experimentally. $* * p<0.001, * * * * p<0.00001$, one-way ANOVA and Student's $t$-test calculations. 
for cells. To monitor the activation of HIF and NFkB pathways after atovaquone treatment, we employed reporter fibroblasts carrying HIF- and NFkB-Luc reporter elements. Vehicle alone (DMSO) control cells were run in parallel. Surprisingly, atovaquone treatment decreases the activation of HIF and NFKB pathways in normal fibroblasts, in a dose-dependent manner (Figure 7B-7C). These results indicate that atovaquone inhibits inflammatory or stress-induced responses, consistent with its safe use in the clinic.
Having firmly established that atovaquone specifically inhibits mitochondrial respiration in MCF7 cancer cells, but not in normal fibroblasts, we then asked if atovaquone could halt the propagation of the CSC population. To this end, MCF7 cells were plated for mammosphere assays in the presence of increasing concentrations of atovaquone or vehicle alone for 5 days. Atovaquone dose-dependently inhibits MCF7 mammosphere formation, with an IC-50 of $\sim 1 \mu \mathrm{M}$ (Figure 8A). To independently validate these results,

A

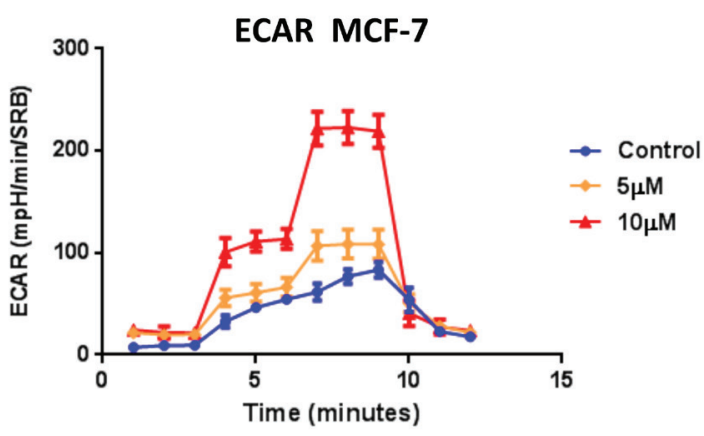

\section{B}

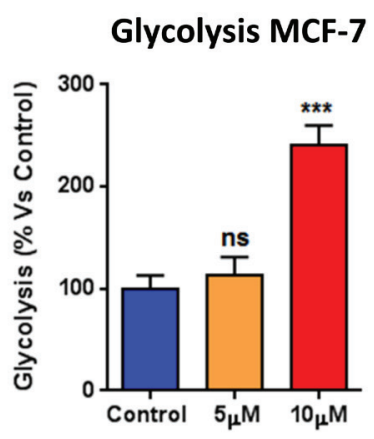

E

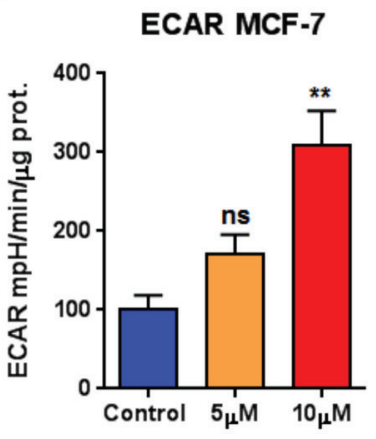

C

Glycolytic reserve MCF-7

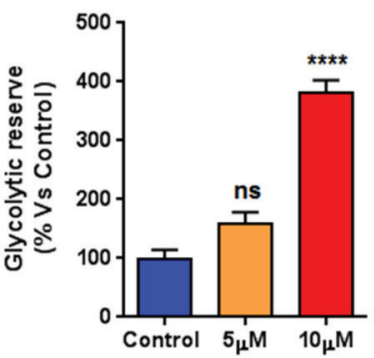

D

\section{Glycolytic reserve capacity MCF-7}

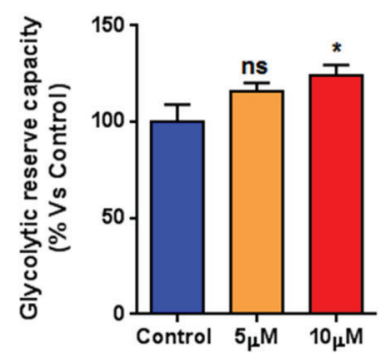

$\mathbf{F}$

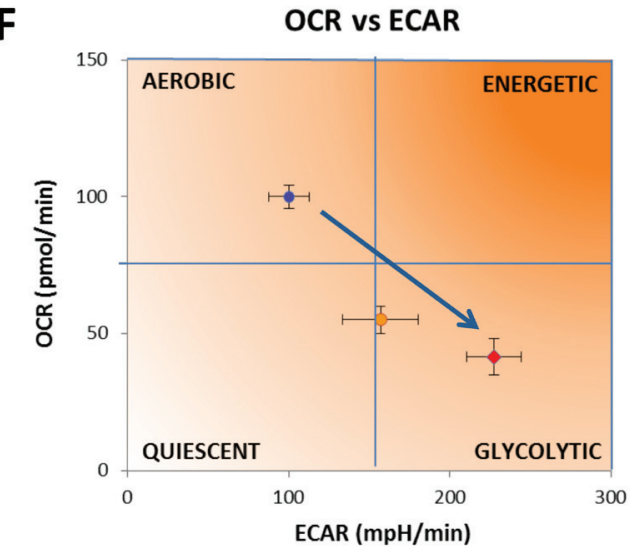

Figure 3: Atovaquone treatment increases glycolysis in MCF7 breast cancer cells. The glycolytic profile of MCF7 cell monolayers treated with atovaquone $(5 \mu \mathrm{M}$ and $10 \mu \mathrm{M})$ for 48 hours was assessed using the Seahorse XF-e 96 analyzer. A. The tracing of 3 independent experiments is shown. B., C., D. Significant increases in glycolysis, glycolytic reserve, and glycolytic reserve capacity were observed experimentally. E. ECAR was also found increased. F. ECAR and OCR were plotted on the same graph. Note that atovaquone treatment $(10 \mu \mathrm{M})$ shifts MCF7 cancer cells from an aerobic state to a glycolytic state. ${ }^{*} p<0.01, * * p<0.001, * * * p<0.0001,{ }^{* * * *} p<$ 0.00001 , ns not significant, one-way ANOVA and Student's $t$-test calculations. 
A

Mitochondrial Deep Red MCF-7

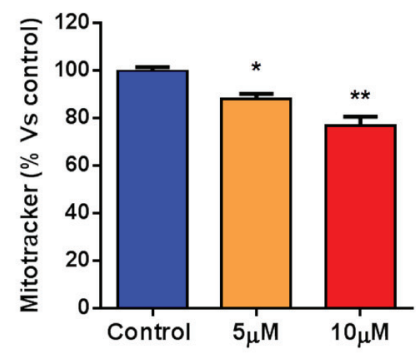

C
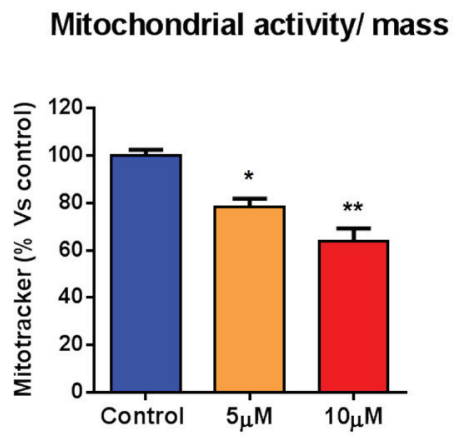

B

Mitochondrial Orange MCF-7

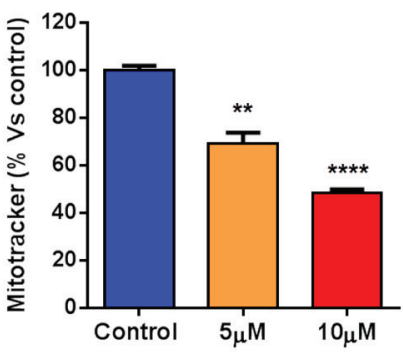

D

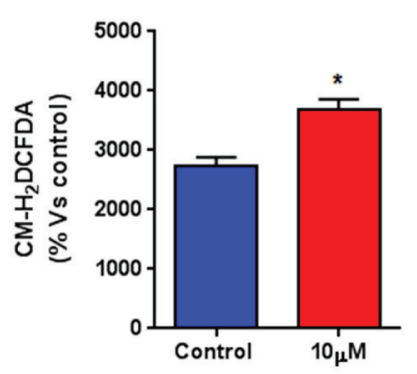

Figure 4: Atovaquone treatment decreases mitochondrial mass and membrane potential, with an increase in ROS levels. MCF 7 cells were treated with atovaquone $(5 \mu \mathrm{M}$ or $10 \mu \mathrm{M})$ for 48 hours, and stained with various metabolic probes and analyzed by FACS. A., B. Atovaquone decreases mitochondrial mass, as assessed with MitoTracker Deep-Red, and mitochondrial membrane potential, as assessed with MitoTracker Orange. C. The ratio of mitochondrial membrane potential (MitoTracker Orange) versus mitochondrial mass (MitoTracker Deep-Red) was calculated, showing that atovaquone significantly decreases mitochondrial membrane potential per mitochondria. D. ROS levels were determined using the CM- $\mathrm{H}_{2}$ DCFDA probe by FACS. Note that atovaquone $(10 \mu \mathrm{M})$ increases ROS levels, as expected. ${ }^{*} p<0.01, * * p<0.001,,{ }^{* * * *} p<0.00001$, one-way ANOVA and Student's $t$-test calculations.

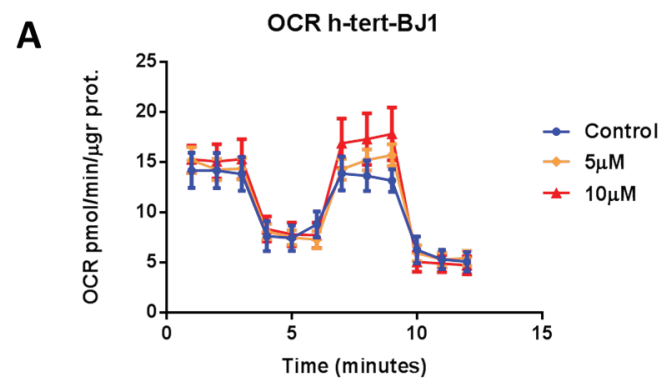

B

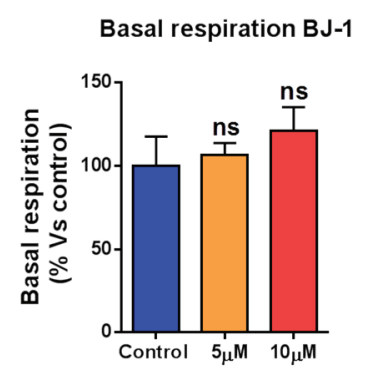

C

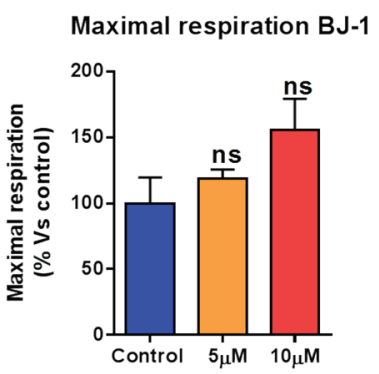

D

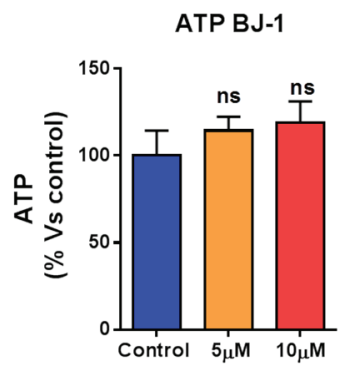

Figure 5: Atovaquone treatment does not affect the mitochondrial respiration of normal human fibroblasts. The metabolic profile of normal human fibroblast (hTERT-BJ1) monolayers treated with atovaquone $(5 \mu \mathrm{M}$ and $10 \mu \mathrm{M})$ for 48 hours was assessed using the Seahorse XF-e96 analyzer. A. The tracing of 3 independent experiments is shown. B., C., D. Note that atovaquone does not significantly reduce basal respiration, maximal respiration, or ATP levels of normal human fibroblasts. ns, not significant; one-way ANOVA and Student's $t$-test calculations. 
the expression of CSC markers (CD24 and CD44) was analyzed by FACS. Notably, atovaquone pre-treatment dose-dependently decreases the CD44+/CD24- ${ }^{\text {low }}$ cell population, which is considered to be the CSC population (Figure 8B). Next, we assessed ALDEFLUOR activity, an independent marker of CSCs, using MCF7 cells pretreated with atovaquone. A specific ALDH inhibitor (diethylaminobenzaldehyde - DEAB) was used for each sample, as a negative control. Note that atovaquone treatment significantly decreases the ALDH-positive cell population by $50 \%$ (Figure $8 \mathrm{C}$ ). Thus, these results indicate that atovaquone treatment also induces apoptosis in MCF7-derived CSCs, during exposure to anchorageindependent conditions (i.e., anoikis), for 12 hours.

We next asked if atovaquone action is specific for CSCs, or if it affects the viability of the total cancer cell population or of normal human fibroblasts. To this end, cell viability was assessed on MCF7 cells and normal human fibroblasts (hTERT-BJ1) treated with atovaquone for 5 days. Interestingly, atovaquone treatment inhibits

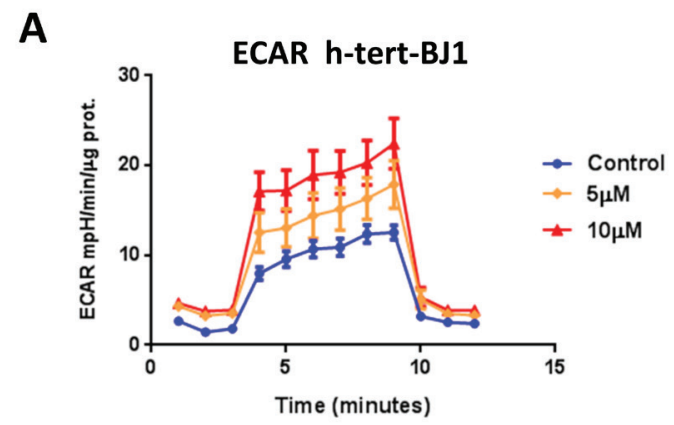

\section{B}

Glycolysis BJ-1

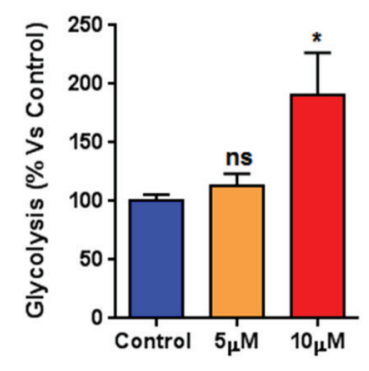

E
C

Glycolytic reserve BJ-1

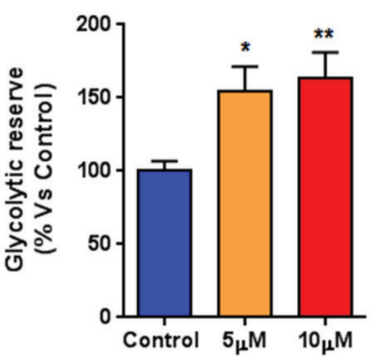

D Glycolytic reserve capacity BJ-1

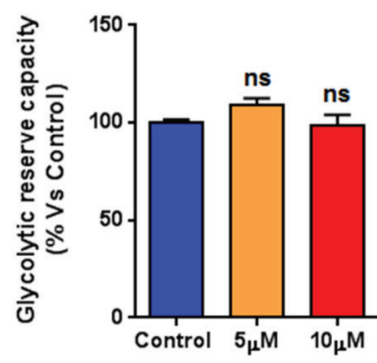

$\mathbf{F}$

ECAR BJ-1
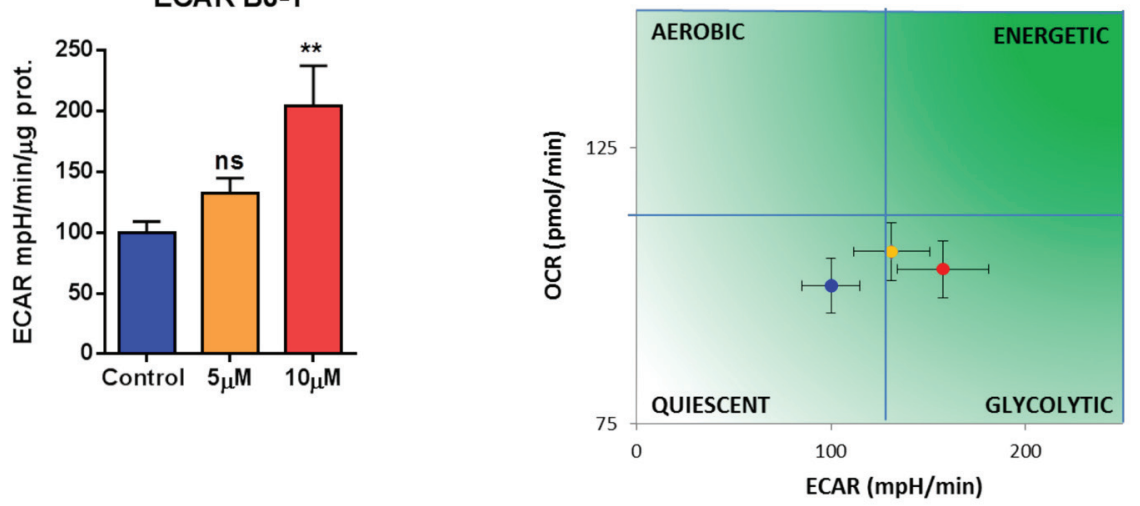

Figure 6: Atovaquone treatment increases glycolysis in normal human fibroblasts. The glycolytic profile of normal human fibroblast (hTERT-BJ1) monolayers treated with atovaquone $(5 \mu \mathrm{M}$ and $10 \mu \mathrm{M})$ for 48 hours was assessed using the Seahorse XF96 analyzer. A. The tracing of 3 independent experiments is shown. B., C., D. Significant increases in glycolysis, and glycolytic reserve were observed experimentally. E. ECAR was also found increased. F. ECAR and OCR were plotted on the same graph. Note that atovaquone treatment does not change the metabolic state of normal human fibroblasts. ${ }^{*} p<0.01,{ }^{* *} p<0.001,{ }^{* * *} p<0.0001,{ }^{* * * *} p<0.00001$, ns not significant, one-way ANOVA and Student's $t$-test calculations. 
A

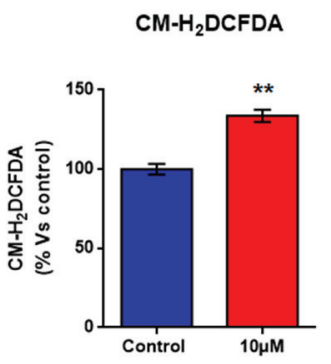

B

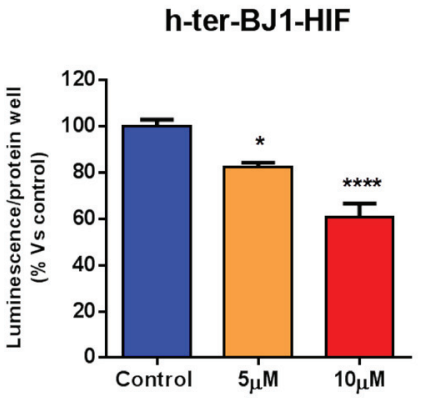

C

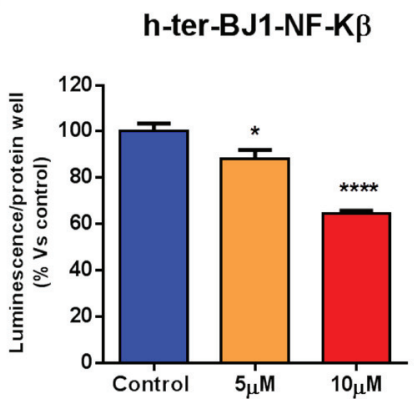

Figure 7: Atovaquone treatment does not induce pro-inflammatory or stress-induced responses in human normal fibroblasts. A. ROS levels were measured in normal human fibroblasts treated with atovaquone (10 $\mu \mathrm{M})$ or DMSO for 48 hours. Note that atovaquone increases ROS levels. B., C. The activation of HIF and NFkB pathways was monitored using Luc-reporter fibroblasts carrying HIF- and NFkB-Luc reporter elements. Luciferase assays were performed on cells treated with atovaquone $(5 \mu \mathrm{M}$ and $10 \mu \mathrm{M})$ or DMSO control for 48 hours. Luminescence was normalized using SRB (total proteins), as a measure of cell viability. Note that atovaquone treatment decreases the activation of $\mathrm{HIF}(\mathrm{B})$ and $\mathrm{NF \kappa B}(\mathrm{C})$ pathways in normal fibroblasts, in a dose-dependent manner. ${ }^{*} p<0.01,{ }^{* *} p<$ $0.001,{ }^{* * * *} p<0.00001$ evaluated with one-way ANOVA.

MCF7 cell viability with an IC-50 of $\sim 10 \mu \mathrm{M}$ (Figure 9A), indicating that atovaquone preferentially inhibits CSCs (compare with Figure 8A), relative to the 'bulk' cancer cells. Thus, atovaquone is about 10 times more potent in the inhibition of CSCs propagation (IC-50 of $\sim 1 \mu \mathrm{M}$ ). Moreover, atovaquone treatment only slightly inhibits normal human fibroblast viability, consistent with its safe use in humans (Figure 9B).

Finally, we asked if atovaquone could still target CSCs in a heterogeneous attached cell population, when they are mixed with the bulk of the cancer cells. To this end, MCF7 cells were pre-treated with atovaquone as

A

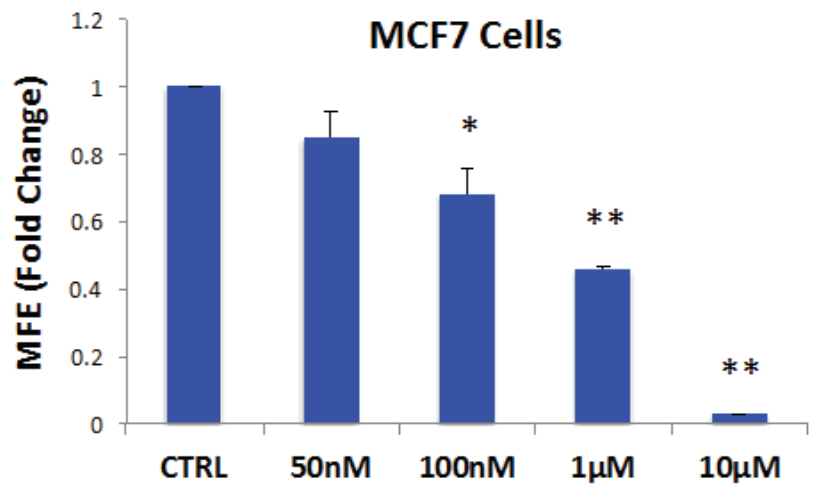

monolayers for 2 days, and then cells were collected and re-plated on low-attachment plates in the absence of atovaquone, for mammosphere assays, or directly assessed for cell viability. Interestingly, atovaquone pre-treatment preferentially inhibits CSCs, in a dose-dependent fashion ( $\sim 85 \%$ inhibition with $10 \mu \mathrm{M}$ atovaquone) (Figure $10 \mathrm{~A})$, with more moderate effects on the viability of bulk cancer cells (only $\sim 30 \%$ inhibition with $10 \mu \mathrm{M}$ atovaquone) (Figure 10B). These results indicate that atovaquone is able to target CSCs also when they are in a heterogeneous attached cell population (IC-50 $\sim \mu \mathrm{M}$ ), when they are mixed with bulk cancer cells. 


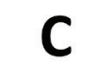

DEAB + ALDEFLUOR

CTRL
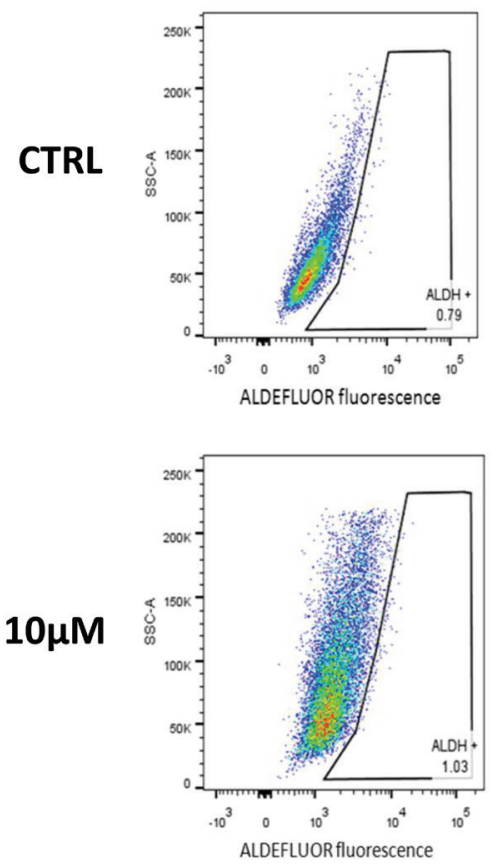

ALDEFLUOR
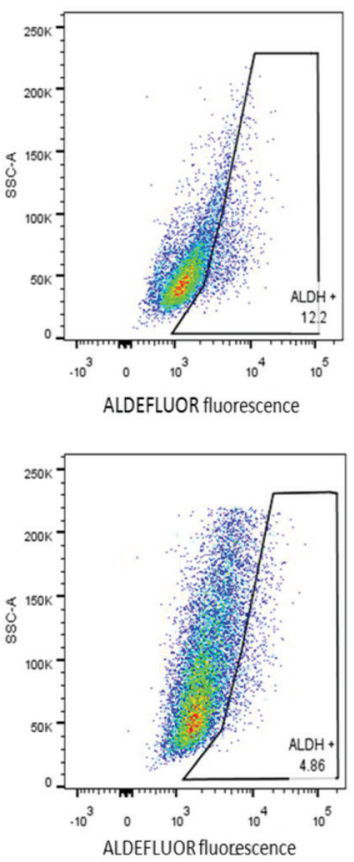

ALDEFLUOR

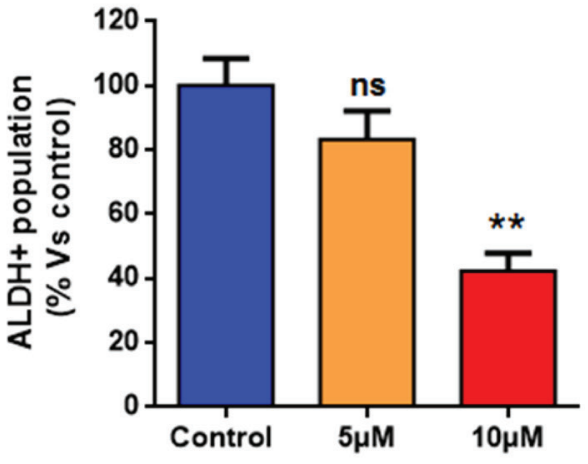

Figure 8: Atovaquone treatment inhibits MCF7-derived CSCs. A. MCF7 cells were plated for mammosphere assays in the presence of increasing concentrations of atovaquone or vehicle alone. Atovaquone dose-dependently inhibits MCF7 mammosphere formation efficiency (MFE) at 5 days, with an IC-50 of $\sim 1 \mu \mathrm{M} .{ }^{*} p<0.05,{ }^{* *} p<0.00001$, evaluated by Student's t test. B. MCF7 cells were pre-treated with atovaquone $(5 \mu \mathrm{M}$ and $10 \mu \mathrm{M})$ as monolayers for 48 hours and then re-plated on low-attachment plates in the absence of atovaquone, for anoikis assay for 12 hours. Expression of CSC markers (CD24 and CD44) was analyzed by FACS. Note that atovaquone pre-treatment dose-dependently decreases the CD44+/CD24-low cell population, which is considered the CSC population. $\mathbf{C}$. MCF7 cells were pre-treated with atovaquone $(5 \mu \mathrm{M}$ and $10 \mu \mathrm{M})$ as monolayers for 48 hours and then assessed for ALDEFLUOR activity, an independent marker of CSCs. Each sample was normalized using diethylaminobenzaldehyde (DEAB), a specific ALDH inhibitor, as negative control. C. The tracing of representative samples is shown. Note that atovaquone treatment decreases the ALDH-positive cell population by $50 \%{ }^{*} p<0.01, * * * * p<0.00001$ evaluated with one-way ANOVA.

A

MCF-7 SRB assay

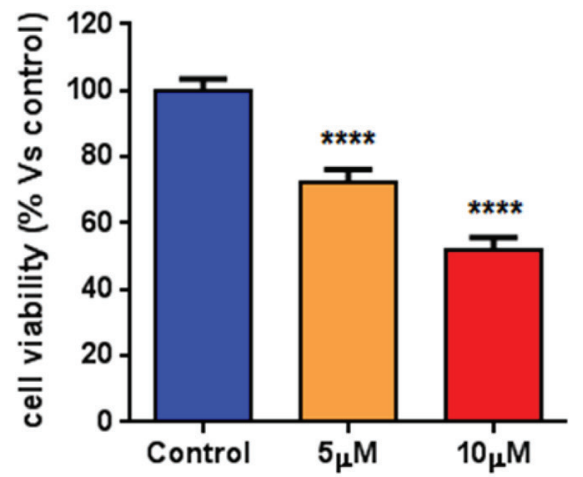

B

\section{BJ1 SRB assay}

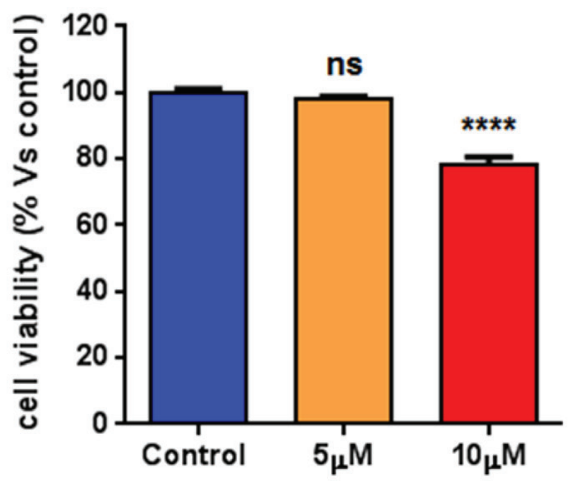

Figure 9: Atovaquone treatment preferentially inhibits CSCs, with minor effects on the viability of normal human fibroblasts. MCF7 cells and normal human fibroblasts (hTERT-BJ1) were treated with atovaquone $(5 \mu \mathrm{M}$ and $10 \mu \mathrm{M})$ for 5 days. Cell viability was assessed by SRB assay. A. Atovaquone treatment inhibits MCF7 cell viability with an IC-50 of $\sim 10 \mu \mathrm{M}$, indicating that atovaquone preferentially inhibits CSCs (compare with Figure 8A), relative to the 'bulk' cancer cells. B. Atovaquone treatment slightly inhibits normal human fibroblast viability, consistent with its safe use in humans. ${ }^{* * *} p<0.00001$, ns not significant, evaluated with oneway ANOVA. 

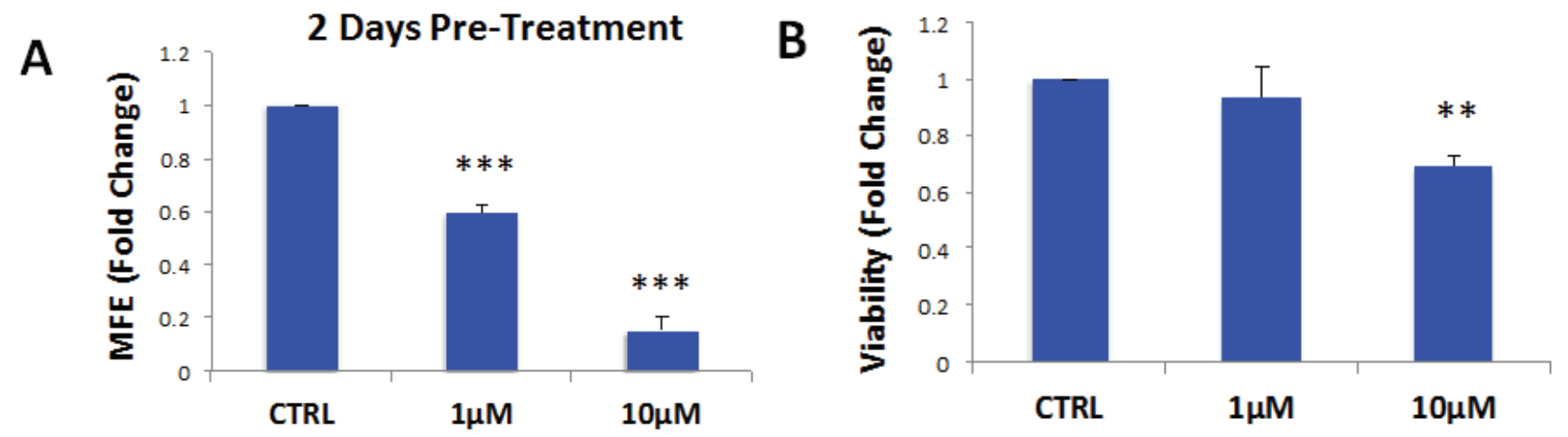

Figure 10: Atovaquone pre-treatment preferentially inhibits CSCs, with minor effects on the viability of bulk cancer cells. MCF7 cells were pre-treated with atovaquone $(1 \mu \mathrm{M}$ and $10 \mu \mathrm{M})$ as monolayers for 2 days. Then, cells re-plated on low-attachment plates in the absence of atovaquone, for mammosphere assay for 5 days, or directly assessed for cell growth and viability. A. Atovaquone pre-treatment inhibits MCF7 cell mammosphere formation, in a dose-dependent fashion $(\sim 85 \%$ inhibition with $10 \mu \mathrm{M}$ atovaquone). $* * * p<$ 0.0001 evaluated by Student's t test B. Under the same conditions, atovaquone has mild effects on the viability of bulk cancer cells $(\sim 30 \%$ inhibition of viability with $10 \mu \mathrm{M}$ atovaquone). ${ }^{* *} p<0.001$ evaluated by Student's $t$ test. MFE: mammosphere forming efficiency.

\section{All Breast Cancers}
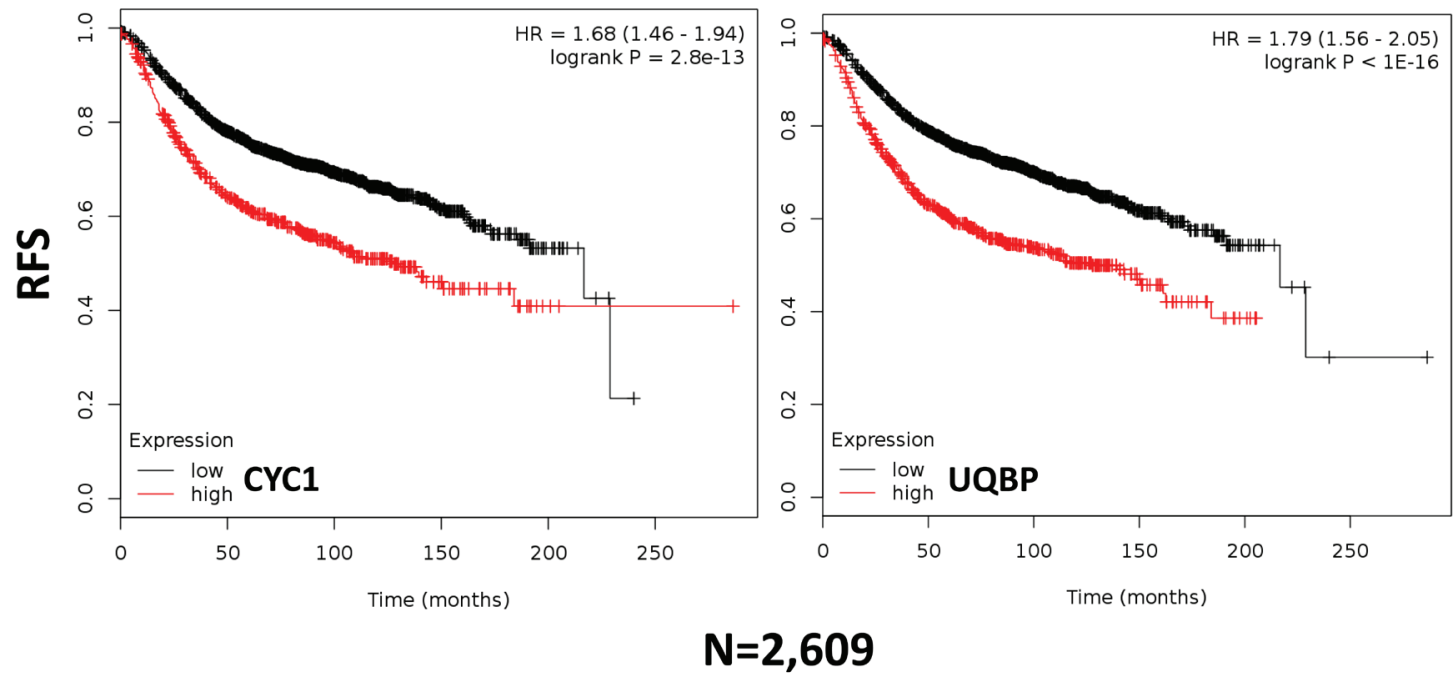

Figure 11: Kaplan-Meier (K-M) analysis of the prognostic value of two components of mitochondrial complex III. Results of recurrence-free survival analysis (RFS) are shown, over nearly a 20-year period of follow-up, for two mitochondrial markers for all breast cancers taken as a single group $(N=2,609)$. Note that higher levels of these two mitochondrial markers are significantly associated with tumor recurrence. See the Methods section for further details of how the analysis was carried out. Similar results were obtained in other sub-types of breast cancer, including ER(+) and ER(-), and are included as Supplementary Figures S1 and S2.

Figure 12: Targeting OXPHOS to eradicate CSCs: Repurposing atovaquone. The propagation of CSCs is thought to underpin the molecular and cellular basis of tumor recurrence, distant metastasis and resistance to chemo- and radio-therapy. Here, we suggest the use of a "safe" mitochondrial OXPHOS inhibitor to eradicate CSCs, which are addicted to mitochondrial function. More specifically, atovaquone (shown at right) inhibits mitochondrial complex III, by effectively competing with the binding of CoQ10 (shown at left).

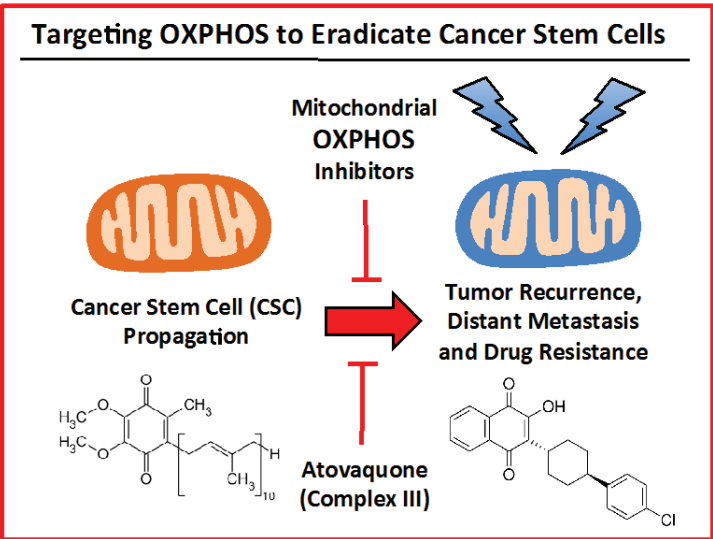


Table 1: High CYC1 mRNA levels are associated with increased tumor recurrence, in both $\operatorname{ER}(+)$ and $\operatorname{ER}(-)$ breast cancer patients.

\begin{tabular}{|c|c|c|c|}
\hline Cancer Subtype & HR & Log-Rank & $\mathbf{N}$ \\
\hline All Subtypes & 1.68 & $2.8 e-13$ & 2,609 \\
\hline ER(-) & 1.53 & 0.002 & 584 \\
\hline ER(-)/Basal & 1.69 & 0.0008 & 436 \\
\hline $\mathrm{ER}(+)$ & 1.65 & $1.1 \mathrm{e}-09$ & 2,025 \\
\hline ER(+)/Endocrine Therapy & 1.73 & 0.0007 & 698 \\
\hline $\begin{array}{l}\text { ER(+)/Endocrine Therapy } \\
\text { Luminal A/LN(+) }\end{array}$ & 1.96 & 0.02 & 145 \\
\hline $\begin{array}{l}\text { ER(+)/Endocrine Therapy } \\
\text { Luminal A/LN(-) }\end{array}$ & 2.94 & 0.0098 & 286 \\
\hline $\begin{array}{l}\text { ER(+)/Endocrine Therapy } \\
\text { Luminal B }\end{array}$ & 1.97 & 0.002 & 247 \\
\hline $\begin{array}{l}\text { ER(+)/Endocrine Therapy } \\
\text { Luminal B/LN(-) }\end{array}$ & 3.11 & 0.001 & 117 \\
\hline
\end{tabular}

CYC1, Cytochrome C1; ER, estrogen receptor; LN, lymph node; HR, hazard ratio; $\mathrm{N}$, the number of patients in a given subtype or group. The vast majority of patients receiving endocrine therapy were treated with tamoxifen.

\section{Validation of the clinical relevance of mitochondrial complex III in human breast cancer patients, in both $\operatorname{ER}(+)$ and $\operatorname{ER}(-)$ epithelial sub-types}

In order to assess the possible clinical relevance of mitochondrial complex III, we determined if different components of the complex show any prognostic value in human breast cancer patient cohorts, with long-term follow-up (approaching 20 years). These results are summarized in Tables 1 and 2. Corresponding KaplanMeier (K-M) analysis curves are included in Figure 11, and as Supplementary Figures S1 and S2 (Panels A-I).

More specifically, high mRNA expression levels of CYC1 (Cytochrome C1) and UQBP (UbiquinolCytochrome C Reductase Binding Protein), key components of complex III, are both associated with significantly reduced progression-free survival (i.e., higher tumor recurrence). Similar results were obtained in both $\mathrm{ER}(+)$ and $\mathrm{ER}(-)$ patients, as well as in ER(+) sub-types (luminal A and luminal B patients). Note that high levels of $\mathrm{CYC1}$ and $\mathrm{UQBP}$ were also associated with progression in patients that received endocrine therapy, which is indicative of a clinical association with endocrine therapyresistance.

Thus, in the future, elevated levels of expression of CYC1 and UQBP could be used to identify highrisk $\mathrm{ER}(+)$ and $\mathrm{ER}(-)$ breast cancer patients that might benefit from treatment with atovaquone, a complex III inhibitor. In this context, CYC1 and UQBP could also be used as companion diagnostics, to guide the use of mitochondrially-targeted atovaquone therapy.

\section{DISCUSSION}

Atovaquone is an FDA-approved anti-parasitic drug that was first developed to target chloroquine-resistant malaria [25]. Currently, its major use is for managing pneumocystis pneumonia (PCP) and toxoplasmosis infections in HIV-positive patients [26]. Structurally, atovaquone resembles $\mathrm{CoQ} 10$ and competitively inhibits its binding to the Cytochrome $b$ subunit (MT-CYB) of mitochondrial complex III [27, 28]. As a consequence, here we explored the possibility that atovaquone could be repurposed for targeting mitochondrial complex III in breast cancer cells (summarized in Figure 12). To test this hypothesis, we first examined its metabolic effects on MCF7 cells, using the Seahorse XF-e96, to measure mitochondrial function and glycolysis. Our results directly show that atovaquone significantly inhibits oxygen consumption and ATP production in the low micromolar range. Moreover, atovaquone treatment significantly induced aerobic glycolysis (a.k.a., the Warburg effect). In this context, we demonstrated that atovaquone reduces both mitochondrial mass and membrane potential, but increased overall ROS production. Importantly, atovaquone potently inhibited the propagation of 
Table 2: High UQBP mRNA levels are associated with increased tumor recurrence, in both $\operatorname{ER}(+)$ and $\operatorname{ER}(-)$ breast cancer patients.

\begin{tabular}{llll}
\hline Cancer Subtype & HR & Log-Rank & N \\
\hline All Subtypes & 1.79 & $<1 \mathrm{e}-16$ & 2,609 \\
ER(-) & 1.86 & $3.6 \mathrm{e}-06$ & 584 \\
ER(-)/Basal & 1.91 & $3.3 \mathrm{e}-05$ & 436 \\
ER(+) & 1.75 & $7.4 \mathrm{e}-13$ & 2,025 \\
ER(+)/Endocrine Therapy & 2.22 & $8.5 \mathrm{e}-08$ & 698 \\
ER(+)/Endocrine Therapy & 3.42 & $1.9 \mathrm{e}-05$ & 145 \\
$\begin{array}{l}\text { Luminal A/LN(+) } \\
\text { ER(+)/Endocrine Therapy }\end{array}$ & 2.04 & 0.016 & 286 \\
Luminal A/LN(-) & & & \\
ER(+)/Endocrine Therapy & 2.28 & 0.0001 & 247 \\
$\begin{array}{l}\text { Luminal B } \\
\text { ER(+)/Endocrine Therapy }\end{array}$ & 4.00 & $4.1 \mathrm{e}-05$ & 117 \\
Luminal B/LN(-) & & & \\
\end{tabular}

UQBP, Ubiquinol-Cytochrome C Reductase Binding Protein; ER, estrogen Receptor; LN, lymph node; HR, hazard ratio; $\mathrm{N}$, the number of patients in a given subtype or group. The vast majority of patients receiving endocrine therapy were treated with tamoxifen.

CSCs, with an IC-50 of $1 \mu \mathrm{M}$, as measured using the mammosphere assay. Interestingly, this concentration is $>60$ times lower than the average serum concentration achieved in patients. Remarkably, atovaquone treatment had little or no effect on normal human fibroblasts.

When atovaquone suspension was administered in humans with food at the standard regimen of $750 \mathrm{mg}$ twice daily, the average steady-state plasma concentration was $21.0 \pm 4.9 \mu \mathrm{g} / \mathrm{mL}$, and the minimum plasma concentration was $16 \pm 3.8 \mu \mathrm{g} / \mathrm{mL}$ [29]. It should be noted that in our experiments we have effectively ablated mammosphere formation with $10 \mu \mathrm{M}$ atovaquone, which corresponds to $3.66 \mu \mathrm{g} / \mathrm{mL}$. Thus, the clinically relevant, therapeutic plasma concentration of atovaquone is 5-times higher than the concentration that completely blocks the expansion of CSCs.

A thorough search of the literature revealed only one previous paper investigating the effects of atovaquone on cancer cell lines. Although mainly focused on the cytotoxicity and apoptosis-inducing activity of atovaquone derivatives, this report shows that atovaquone effectively inhibited the growth of Du145 prostate cancer cells, with an IC-50 of approximately $30 \mu \mathrm{M}$ [30]. So, our current results are consistent with these overall findings. However, these authors did not evaluate the effects of atovaquone on CSCs.

Interestingly, it is well known that atovaquone binds directly to the Cytochrome $\mathrm{b}$ component of the Cytochrome bc1 complex, in the mitochondria of malarial parasites. This has been further verified by a mutational analysis and by determining the crystal structure of atovaquone bound to the Cytochrome $\mathrm{b}$ molecule, also known as MT-CYB [31, 32]. However, very little is known about the role of MT-CYB and the Cytochrome bc1 complex in cancer.

Genetic evidence of a role for MT-CYB in cancer comes from studies on breast and colon cancers. A recent study used targeted sequencing of mitochondrial DNA in high-risk breast cancer patients negative for BRCA1/2 mutations to provide new clinical evidence for MT-CYB variants as a risk factor for hereditary breast cancers [33]. Interestingly, they observed that two mitochondrial genes, namely MT-ATP6 (complex V) and MT-CYB (complex III) showed the highest number of variants in the highrisk breast cancer patients. In further support of these findings, 4 homoplasmic and 6 heteroplasmic alterations were found in the mitochondrial DNA of human colon cancer cell lines; among these changes, a homoplasmic mutation in MT-CYB (G14804A) results in amino acid substitutions in highly conserved residues [34]. Two homoplasmic mutations in MT-CYB [G14985A (R80H) and $\mathrm{T} 15572 \mathrm{C}(\mathrm{F} 276 \mathrm{~L})]$ were independently observed in another cohort of human colon cancer patients [35]. The fact that these mutations are homoplasmic indicates that they provide both a strong replicative and proliferative advantage. Interestingly, the two latter mutations in MTCYB did not result in any observable defects in OXPHOS, indicating that the mitochondria bearing these mutations 
remained highly functional [35].

MT-CYB mutations have also been detected in human bladder carcinomas [36, 37]. For example, a 21bp in-frame deletion results in a loss of 7-amino acids in the MT-CYB protein product. Cells over-expressing this "activated mutant" of MT-CYB showed significant increases in cell proliferation and tumor growth, due to NFkB hyper-activation, increased oxygen consumption rates and resistance to apoptosis. This activated mutant of MT-CYB, specifically associated with bladder cancer, also functionally increased anchorage-independent growth and mitochondrial biogenesis, as well as mt-DNA content [36, 37].

The Cytochrome bc1 complex contains two major subunits: Cytochrome b (MT-CYB) and Cytochrome $\mathrm{c} 1$ (CYC1). Very little is known about the role of CYC1 in cancer pathogenesis. However, silencing of CYC1 (using an shRNA approach) in osteosarcoma cell lines effectively inhibits cellular proliferation, sensitizes the cells to apoptotic cell death and inhibits their ability to form tumors in xenograft models [38]. In their model system, the authors also demonstrated that $\mathrm{CYC} 1$ silencing significantly reduced mitochondrial complex III activity.

Interestingly, several reports indicate that the expression levels of mitochondrial complex III subunits are altered in human breast cancers [39, 40]. For example, ubiquinol cytochrome c reductase (UQCRFS1) is amplified in a subset of breast cancers and is associated with higher tumor grade [40]. In addition, there appears to be a relationship between tamoxifen-sensitivity and complex III. More specifically, inhibition of mitochondrial complex III enhances the cytotoxicity of tamoxifen in MCF7 cells [41]. This synergy may stem from the observation that tamoxifen may act directly on mitochondria, as an inhibitor of complex III function [42].

Taken together with our current data, these results suggest that atovaquone treatment may be an effective new strategy for targeting the Cytochrome bc 1 complex (especially MT-CYB and CYC1) in cancer, to prevent the proliferative expansion of CSCs and tumor growth. Further pre-clinical studies to test atovaquone efficacy are clearly warranted. In direct support of the idea that targeting mitochondrial complex III is a promising therapeutic strategy, Kwon, Jung and colleagues have developed a series of small molecules that successfully inhibited the activity of complex III (UQBP; ubiquinol-cytochrome c reductase binding protein) [43,44]. Interestingly, these small molecules also dramatically reduced tumor growth in pre-clinical xenograft models (harboring U87MG glioblastoma cells), without showing any in vitro and in vivo toxicity. However, these novel molecules will need to undergo phase I clinical trials.

In contrast, atovaquone is already FDA-approved and can immediately enter phase II clinical trails, potentially saving 10 years in development time and millions of dollars. Thus, the repurposing of atovaquone may be a more effective translational approach, to more rapidly bring mitochondrial complex III inhibitors to the clinic.

\section{MATERIALS AND METHODS}

\section{Materials}

MCF7 breast cancer cell lines were purchased from the ATCC. Human immortalized fibroblasts (hTERT-BJ1) were purchased from Clontech, Inc. Cells were cultured in Dulbecco's modified Eagle's medium (DMEM), supplemented with $10 \%$ FBS (fetal bovine serum), 2 mM GlutaMAX, and $1 \%$ Pen-Strep in a $37^{\circ} \mathrm{C}$ humidified atmosphere containing $5 \% \mathrm{CO}_{2}$, unless otherwise noted. Gibco-brand cell culture media (DMEM/F12) was purchased from Life Technologies. Atovaquone was purchased from Sigma-Aldrich.

\section{Seahorse XFe-96 metabolic flux analysis}

Extracellular acidification rates (ECAR) and realtime oxygen consumption rates (OCR) for MCF7 cells and fibroblasts treated with atovaquone were determined using the Seahorse Extracellular Flux (XFe-96) analyzer (Seahorse Bioscience, MA, USA) [17]. 10,000 cells per well were seeded into XFe-96 well cell culture plates, and incubated overnight to allow attachment. Then, cells were treated with atovaquone $(5 \mu \mathrm{M}$ and $10 \mu \mathrm{M})$ for 48 hours. Vehicle alone (DMSO) control cells were processed in parallel. After 48 hours of incubation, cells were washed in pre-warmed XF assay media (or for OCR measurement, $\mathrm{XF}$ assay media supplemented with $10 \mathrm{mM}$ glucose, $1 \mathrm{mM}$ Pyruvate, $2 \mathrm{mM}$ L-glutamine and adjusted at $7.4 \mathrm{pH}$ ). Cells were then maintained in $175 \mu \mathrm{L} /$ well of XF assay media at $37^{\circ} \mathrm{C}$, in a non- $\mathrm{CO}_{2}$ incubator for 1 hour. During the incubation time, we loaded $25 \mu \mathrm{L}$ of $80 \mathrm{mM}$ glucose, $9 \mu \mathrm{M}$ oligomycin, and 1M 2-deoxyglucose (for ECAR measurement) or $10 \mu \mathrm{M}$ oligomycin, $9 \mu \mathrm{M} \mathrm{FCCP}, 10 \mu \mathrm{M}$ rotenone, $10 \mu \mathrm{M}$ antimycin A (for OCR measurement), in XF assay media into the injection ports in the XFe96 sensor cartridge. Measurements were normalized by protein content (SRB or Bradford assay). Data set was analyzed by XFe-96 software and GraphPad Prism software, using one-way ANOVA and Student's $t$-test calculations. All experiments were performed three times independently.

\section{Mitochondrial staining}

Mitochondrial activity was assessed with MitoTracker Orange (\#M7510, Invitrogen), whose accumulation in mitochondria is dependent upon 
membrane potential. Mitochondrial mass was determined using MitoTracker Deep-Red (\#M22426, Invitrogen), localizing to mitochondria regardless of mitochondrial membrane potential. MCF7 cells were treated with atovaquone $(5 \mu \mathrm{M}$ and $10 \mu \mathrm{M})$ for 48 hours. Vehicle alone (DMSO) control cells were processed in parallel. After 48 hours, cells were incubated with pre-warmed MitoTracker staining solution (diluted in PBS/CM to a final concentration of $10 \mathrm{nM}$ ) for $30-60$ minutes at $37^{\circ} \mathrm{C}$. All subsequent steps were performed in the dark. Cells were washed in PBS, harvested, and re-suspended in $300 \mu \mathrm{L}$ of PBS/CM. Cells were then analyzed by flow cytometry using Fortessa (BD Bioscience). Data analysis was performed using FlowJo software.

\section{ROS staining}

Reactive oxygen species (ROS) production was measured using CM-H DCFDA (C6827, Invitrogen), a cell-permeable probe that is non-fluorescent until oxidation within the cell. Cells were treated with $10 \mu \mathrm{M}$ atovaquone for 48 hours. Vehicle alone (DMSO) control cells were processed in parallel. After 48 hours, cells were washed with PBS, and incubated with CM-H 2 DCFDA (diluted in PBS/CM to a final concentration of $1 \mu \mathrm{M}$ ) for 20 minutes at $37^{\circ} \mathrm{C}$. All subsequent steps were performed in the dark. Cells were rinsed, harvested, and re-suspended in PBS/CM. Cells were then analyzed by flow cytometry using the Fortessa (BD Bioscience). ROS levels were estimated by using the mean fluorescent intensity of the viable cell population. The results were analyzed using FlowJo software (Tree star Inc.).

\section{Mammosphere culture}

A single cell suspension was prepared using enzymatic (1x Trypsin-EDTA, Sigma Aldrich, \#T3924), and manual disaggregation (25 gauge needle) [45]. Cells were plated at a density of 500 cells $/ \mathrm{cm}^{2}$ in mammosphere medium (DMEM-F12/ B27/20ng/ml EGF/PenStrep) in non-adherent conditions, in culture dishes coated with (2-hydroxyethylmethacrylate) (poly-HEMA, Sigma, \#P3932). Then, cells were treated with increasing concentrations of atovaquone (range $50 \mathrm{nM}$ to $10 \mu \mathrm{M}$ ). Vehicle alone (DMSO) control cells were processed in parallel. Cells were grown for 5 days and maintained in a humidified incubator at $37^{\circ} \mathrm{C}$. After 5 days for culture, spheres $>50 \mu \mathrm{m}$ were counted using an eye piece graticule, and the percentage of cells plated which formed spheres was calculated and is referred to as percentage mammosphere formation, and was normalized to one $(1=$ $100 \%$ MFE). Similar results were also obtained when cells were seeded at a density of 200 cells $/ \mathrm{cm}^{2}$.

\section{CD44/CD24 analysis}

$1 \times 10^{5}$ MCF7 cells were treated with atovaquone ( $5 \mu \mathrm{M}$ and $10 \mu \mathrm{M}$ ) for 48 hours in 6-well plates, grown as a monolayer. Then, cells were trypsinized and seeded in low-attachment plates in mammosphere media. After 12 hours, MCF7 cells were spun down and incubated with CD24 (IOTest CD24-PE, Beckman Coulter) and CD44 (APC mouse Anti-Human CD44, BD Pharmingen cat.559942) antibodies for 15 minutes on ice. Cells were rinsed twice and incubated with LIVE/DEAD dye (Fixable Dead Violet reactive dye; Invitrogen) for 10 minutes. Samples were then analyzed by FACS (Fortessa, BD Bioscence). Only the live population, as identified by the LIVE/DEAD dye staining, was analyzed for CD24/CD44 expression. Data were analyzed using FlowJo software.

\section{ALDEFLUOR assay and separation of the ALDH- positive population by FACS}

ALDH activity was assessed in MCF7 cells after treatment with atovaquone $(5 \mu \mathrm{M}$ and $10 \mu \mathrm{M})$ or vehicle control. The ALDEFLUOR kit (StemCell Technologies, Vancouver, Canada) was used to isolate the population with high ALDH enzymatic activity by FACS (Fortessa, BD Bioscence). Briefly, $1 \times 10^{5}$ MCF7 cells were incubated in $1 \mathrm{ml}$ ALDEFLUOR assay buffer containing ALDH substrate $(5 \mu \mathrm{l} / \mathrm{ml})$ for 40 minutes at $37^{\circ} \mathrm{C}$. In each experiment, a sample of cells was stained under identical conditions with $30 \mu \mathrm{M}$ of diethylaminobenzaldehyde (DEAB), a specific ALDH inhibitor, as negative control. The ALDEFLUOR-positive population was established in according to the manufacturer's instructions and was evaluated in $2 \times 10^{4}$ cells.

\section{Pre-treatment of monolayers with atoqvaquone}

After treatment with atovaquone in monolayers (1 $\mu \mathrm{M}$ or $10 \mu \mathrm{M}$ for 2 days), MCF7 cells were trypsinized and seeded for mammosphere cultures. In parallel, cells were assessed for cell viability or cell growth. Cell growth was quantitatively measured using an Automated Cell Counter (Biorad), and cell viability was assessed by labeling with Trypan blue (Sigma).

\section{SRB assay}

Cell viability was assessed by sulphorhodamine (SRB) assay, based on the measurement of cellular protein content. After treatment with atovaquone for 5 days in 96 well plates, cells were fixed with $10 \%$ trichloroacetic acid (TCA) for 1 hour in cold room, and dried overnight at room temperature. Then, cells were incubated with SRB for $15 \mathrm{~min}$, washed twice with $1 \%$ acetic acid, and air 
dried for at least 3 hour. Finally, the protein-bound dye was dissolved in $10 \mathrm{mM}$ Tris $\mathrm{pH} 8.8$ solution and read using a plate reader at $540 \mathrm{~nm}$.

\section{Evaluation of HIF and NFKB signaling pathways}

The Cignal Lenti reporter assay (Luc) system (Qiagen) was chosen for monitoring HIF- and NFKB-Luc pathway activity in fibroblasts, as we previously described [46, 47]. Luciferase assay (E1501, Promega) was performed in luciferase reporter hTERT-BJ1 cells treated with atovaquone. Briefly, $1 \times 10^{4}$ hTERT-BJ1 reporter cells were seeded in black-walled 96-well plates and then were treated with atovaquone $(5 \mu \mathrm{M}$ and $10 \mu \mathrm{M})$ for 48 hours. Vehicle alone (DMSO) control cells were run in parallel. Six replicates were used for each condition. After 48 hours, luciferase assay was performed according to the manufacturer's instructions. Light signal was acquired for 2 minutes in photons/second in the Xenogen VivoVision IVIS Lumina (Caliper Life Sciences), and the results were analyzed using the Living Image 3.2 software (Caliper Life Sciences). Luminescence was normalized using SRB (total proteins), as a measure of cell viability.

\section{Statistical analysis}

Statistical significance was measured using the analysis of variance (ANOVA) test or $t$-test. $\mathrm{P} \leq 0.05$ was considered significant and all statistical tests were twosided.

\section{Kaplan-Meier (K-M) analyses}

To perform K-M analysis, we used an open-access online survival analysis tool to interrogate publically available microarray data from up to 2,609 breast cancer patients. This allowed us to determine their prognostic value. Biased and outlier array data were excluded from the analysis. Hazard-ratios were calculated, at the best auto-selected cut-off, and p-values were calculated using the logrank test and plotted in R. K-M curves were generated online using the K-M-plotter (as high-resolution TIFF files), using univariate analysis: http://kmplot.com/ analysis/index.php?p $=$ service\&cancer $=$ breast. This allowed us to directly perform in silico validation of these mitochondrial biomarker candidates.

\section{ACKNOWLEDGMENTS AND FUNDING}

We thank the University of Manchester for providing start-up funds that contributed to the success of this study. The Sotgia and Lisanti Laboratories were supported, in part, by funding from the European Union (ERC Advanced Grant), Breast Cancer Now, and the
Manchester Cancer Research Centre (MCRC). Ubaldo E. Martinez- Outschoorn was supported by the National Cancer Institute (NCI) of the National Institutes of Health (NIH), under Award Number K08-CA17519301A1. Rebecca Lamb was supported by a grant from the Margaret Q. Landenberger Research Foundation.

We are especially grateful to Professor Sir Salvador Moncada (University of Manchester) for initially suggesting that we might want to test atovaquone in our assay systems, to compare it with other anti-mitochondrial agents, in parallel.

\section{CONFLICTS OF INTEREST}

There is no conflict of interest.

\section{REFERENCES}

1. Fillmore CM and Kuperwasser C. Human breast cancer cell lines contain stem-like cells that self-renew, give rise to phenotypically diverse progeny and survive chemotherapy. Breast cancer research. 2008; 10:R25.

2. Zhang $M$ and Rosen JM. Stem cells in the etiology and treatment of cancer. Current opinion in genetics \& development. 2006; 16:60-64.

3. Li X, Lewis MT, Huang J, Gutierrez C, Osborne CK, Wu MF, Hilsenbeck SG, Pavlick A, Zhang X, Chamness GC, Wong H, Rosen $\mathrm{J}$ and Chang JC. Intrinsic resistance of tumorigenic breast cancer cells to chemotherapy. Journal of the National Cancer Institute. 2008; 100:672-679.

4. Xin H, Kong Y, Jiang X, Wang K, Qin X, Miao ZH, Zhu $\mathrm{Y}$ and Tan W. Multi-drug-resistant cells enriched from chronic myeloid leukemia cells by Doxorubicin possess tumor-initiating-cell properties. Journal of pharmacological sciences. 2013; 122:299-304.

5. Scopelliti A, Cammareri P, Catalano V, Saladino V, Todaro M and Stassi G. Therapeutic implications of Cancer Initiating Cells. Expert opinion on biological therapy. 2009; 9:1005-1016.

6. Easwaran H, Tsai HC and Baylin SB. Cancer epigenetics: tumor heterogeneity, plasticity of stem-like states, and drug resistance. Molecular cell. 2014; 54:716-727.

7. Takebe N, Miele L, Harris PJ, Jeong W, Bando H, Kahn M, Yang SX and Ivy SP. Targeting Notch, Hedgehog, and Wnt pathways in cancer stem cells: clinical update. Nature reviews Clinical oncology. 2015; 12:445-64. doi: 10.1038/ nrclinonc.2015.61.

8. Zhao C, Chen A, Jamieson CH, Fereshteh M, Abrahamsson A, Blum J, Kwon HY, Kim J, Chute JP, Rizzieri D, Munchhof M, VanArsdale T, Beachy PA and Reya T. Hedgehog signalling is essential for maintenance of cancer stem cells in myeloid leukaemia. Nature. 2009; 458:776779 .

9. Singh A and Settleman J. EMT, cancer stem cells and drug 
resistance: an emerging axis of evil in the war on cancer. Oncogene. 2010; 29:4741-4751.

10. Takahashi-Yanaga F and Kahn M. Targeting Wnt signaling: can we safely eradicate cancer stem cells? Clinical cancer research. 2010; 16:3153-3162.

11. Al-Hajj M, Becker MW, Wicha M, Weissman I and Clarke MF. Therapeutic implications of cancer stem cells. Current opinion in genetics \& development. 2004; 14:43-47.

12. Sell S. Stem cell origin of cancer and differentiation therapy. Critical reviews in oncology/hematology. 2004; 51:1-28.

13. Scadden DT. The stem-cell niche as an entity of action. Nature. 2006; 441:1075-1079.

14. Yang ZJ and Wechsler-Reya RJ. Hit 'em where they live: targeting the cancer stem cell niche. Cancer cell. 2007; 11:3-5.

15. Deblois $\mathrm{G}$ and Giguere V. Functional and physiological genomics of estrogen-related receptors (ERRs) in health and disease. Biochimica et biophysica acta. 2011; 1812:10321040.

16. Deblois G, St-Pierre J and Giguere V. The PGC-1/ERR signaling axis in cancer. Oncogene. 2013; 32:3483-3490.

17. De Luca A, Fiorillo M, Peiris-Pages M, Ozsvari B, Smith DL, Sanchez-Alvarez R, Martinez-Outschoorn UE, Cappello AR, Pezzi V, Lisanti MP and Sotgia F. Mitochondrial biogenesis is required for the anchorageindependent survival and propagation of stem-like cancer cells. Oncotarget. 2015; 6:14777-95. doi: 10.18632/ oncotarget. 4401 .

18. Lamb R, Ozsvari B, Lisanti CL, Tanowitz HB, Howell A, Martinez-Outschoorn UE, Sotgia F and Lisanti MP. Antibiotics that target mitochondria effectively eradicate cancer stem cells, across multiple tumor types: Treating cancer like an infectious disease. Oncotarget. 2015; 10;6:4569-84. doi: 10.18632/oncotarget.3174.

19. Skrtic M, Sriskanthadevan S, Jhas B, Gebbia M, Wang X, Wang Z, Hurren R, Jitkova Y, Gronda M, Maclean N, Lai CK, Eberhard Y, Bartoszko J, Spagnuolo P, Rutledge AC, Datti A, et al. Inhibition of mitochondrial translation as a therapeutic strategy for human acute myeloid leukemia. Cancer cell. 2011; 20:674-688.

20. Lamb R, Harrison H, Hulit J, Smith DL, Lisanti MP and Sotgia F. Mitochondria as new therapeutic targets for eradicating cancer stem cells: Quantitative proteomics and functional validation via MCT1/2 inhibition. Oncotarget. 2014; 5:11029-11037. doi: 10.18632/oncotarget.2789.

21. Sancho P, Burgos-Ramos E, Tavera A, Bou Kheir T, Jagust P, Schoenhals M, Barneda D, Sellers K, Campos-Olivas R, Grana O, Viera CR, Yuneva M, Sainz B, Jr. and Heeschen C. MYC/PGC-1alpha Balance Determines the Metabolic Phenotype and Plasticity of Pancreatic Cancer Stem Cells. Cell metabolism. 2015; 22:590-605.

22. Gupta PB, Onder TT, Jiang G, Tao K, Kuperwasser C, Weinberg RA and Lander ES. Identification of selective inhibitors of cancer stem cells by high-throughput screening. Cell. 2009; 138:645-659.

23. Manago A, Leanza L, Carraretto L, Sassi N, Grancara S, Quintana-Cabrera R, Trimarco V, Toninello A, Scorrano L, Trentin L, Semenzato G, Gulbins E, Zoratti M and Szabo I. Early effects of the antineoplastic agent salinomycin on mitochondrial function. Cell death \& disease. 2015; 6:e1930.

24. Srivastava IK, Rottenberg H and Vaidya AB. Atovaquone, a broad spectrum antiparasitic drug, collapses mitochondrial membrane potential in a malarial parasite. The Journal of biological chemistry. 1997; 272:3961-3966.

25. Radloff PD, Philipps J, Nkeyi M, Hutchinson D and Kremsner PG. Atovaquone and proguanil for Plasmodium falciparum malaria. Lancet. 1996; 347:1511-1514.

26. Hughes W, Leoung G, Kramer F, Bozzette SA, Safrin S, Frame P, Clumeck N, Masur H, Lancaster D, Chan C and et al. Comparison of atovaquone (566C80) with trimethoprimsulfamethoxazole to treat Pneumocystis carinii pneumonia in patients with AIDS. The New England journal of medicine. 1993; 328:1521-1527.

27. Fry M and Pudney M. Site of action of the antimalarial hydroxynaphthoquinone, 2-[trans-4-(4'-chlorophenyl) cyclohexyl]-3-hydroxy-1,4-naphthoquinone (566C80). Biochemical pharmacology. 1992; 43:1545-1553.

28. Mather MW, Darrouzet E, Valkova-Valchanova M, Cooley JW, McIntosh MT, Daldal F and Vaidya AB. Uncovering the molecular mode of action of the antimalarial drug atovaquone using a bacterial system. The Journal of biological chemistry. 2005; 280:27458-27465.

29. Falloon J, Sargent S, Piscitelli SC, Bechtel C, LaFon SW, Sadler B, Walker RE, Kovacs JA, Polis MA, Davey RT, Jr., Lane HC and Masur H. Atovaquone suspension in HIVinfected volunteers: pharmacokinetics, pharmacodynamics, and TMP-SMX interaction study. Pharmacotherapy. 1999; 19:1050-1056.

30. Zhou J, Duan L, Chen H, Ren X, Zhang Z, Zhou F, Liu J, Pei D and Ding K. Atovaquone derivatives as potent cytotoxic and apoptosis inducing agents. Bioorganic \& medicinal chemistry letters. 2009; 19:5091-5094.

31. Srivastava IK, Morrisey JM, Darrouzet E, Daldal F and Vaidya AB. Resistance mutations reveal the atovaquonebinding domain of cytochrome $\mathrm{b}$ in malaria parasites. Molecular microbiology. 1999; 33:704-711.

32. Nayak SK, Mallik SB, Kanaujia SP, Sekar K, Ranganathan KR, Ananthalakshmi V, Jeyaraman G, Saralaya SS, Rao KS, Shridhara K, Nagarajan K and Row TNG. Crystal structures and binding studies of atovaquone and its derivatives with cytochrome bc(1): a molecular basis for drug design. Crystengcomm. 2013; 15:4871-4884.

33. Blein S, Barjhoux L, investigators G, Damiola F, Dondon MG, Eon-Marchais S, Marcou M, Caron O, Lortholary A, Buecher B, Vennin P, Berthet P, Nogues C, Lasset C, Gauthier-Villars M, Mazoyer S, et al. Targeted Sequencing 
of the Mitochondrial Genome of Women at High Risk of Breast Cancer without Detectable Mutations in BRCA1/2. PloS one. 2015; 10:e136192.

34. Chihara N, Amo T, Tokunaga A, Yuzuriha R, Wolf AM, Asoh S, Suzuki H, Uchida E and Ohta S. Mitochondrial DNA alterations in colorectal cancer cell lines. Journal of Nippon Medical School. 2011; 78:13-21.

35. Polyak K, Li Y, Zhu H, Lengauer C, Willson JK, Markowitz $\mathrm{SD}$, Trush MA, Kinzler KW and Vogelstein B. Somatic mutations of the mitochondrial genome in human colorectal tumours. Nature genetics. 1998; 20:291-293.

36. Dasgupta S, Hoque MO, Upadhyay S and Sidransky D. Mitochondrial cytochrome B gene mutation promotes tumor growth in bladder cancer. Cancer research. 2008; 68:700706.

37. Dasgupta S, Hoque MO, Upadhyay S and Sidransky D. Forced cytochrome B gene mutation expression induces mitochondrial proliferation and prevents apoptosis in human uroepithelial SV-HUC-1 cells. International journal of cancer. 2009; 125:2829-2835.

38. Li G, Fu D, Liang W, Fan L, Chen K, Shan L, Hu S, Ma X, Zhou K and Cheng B. CYC1 silencing sensitizes osteosarcoma cells to TRAIL-induced apoptosis. Cellular physiology and biochemistry. 2014; 34:2070-2080.

39. Putignani L, Raffa S, Pescosolido R, Aimati L, Signore F, Torrisi MR and Grammatico P. Alteration of expression levels of the oxidative phosphorylation system (OXPHOS) in breast cancer cell mitochondria. Breast cancer research and treatment. 2008; 110:439-452.

40. Ohashi Y, Kaneko SJ, Cupples TE and Young SR. Ubiquinol cytochrome c reductase (UQCRFS1) gene amplification in primary breast cancer core biopsy samples. Gynecologic oncology. 2004; 93:54-58.

41. Theodossiou TA, Yannakopoulou K, Aggelidou C and Hothersall JS. Tamoxifen subcellular localization; observation of cell-specific cytotoxicity enhancement by inhibition of mitochondrial ETC complexes I and III. Photochemistry and photobiology. 2012; 88:1016-1022.
42. Tuquet C, Dupont J, Mesneau A and Roussaux J. Effects of tamoxifen on the electron transport chain of isolated rat liver mitochondria. Cell biology and toxicology. 2000; 16:207-219.

43. Jung HJ, Kim KH, Kim ND, Han G and Kwon HJ. Identification of a novel small molecule targeting UQCRB of mitochondrial complex III and its anti-angiogenic activity. Bioorganic \& medicinal chemistry letters. 2011; 21:1052-1056.

44. Jung HJ, Cho M, Kim Y, Han G and Kwon HJ. Development of a novel class of mitochondrial ubiquinolcytochrome c reductase binding protein (UQCRB) modulators as promising antiangiogenic leads. Journal of medicinal chemistry. 2014; 57:7990-7998.

45. Shaw FL, Harrison H, Spence K, Ablett MP, Simoes BM, Farnie G and Clarke RB. A detailed mammosphere assay protocol for the quantification of breast stem cell activity. Journal of mammary gland biology and neoplasia. 2012; 17:111-117.

46. Fiorillo M, Verre AF, Iliut M, Peiris-Pages M, Ozsvari B, Gandara R, Cappello AR, Sotgia F, Vijayaraghavan A and Lisanti MP. Graphene oxide selectively targets cancer stem cells, across multiple tumor types: implications for nontoxic cancer treatment, via "differentiation-based nanotherapy”. Oncotarget. 2015; 6:3553-3562. doi: 10.18632/ oncotarget.3348.

47. Peiris-Pages M, Sotgia F and Lisanti MP. Chemotherapy induces the cancer-associated fibroblast phenotype, activating paracrine hedgehog-GLI signaling in breast cancer cells. Oncotarget. 2015; 6:10728-45. doi: 10.18632/ oncotarget. 3828 . 